\title{
Carbamazepine-Induced Hematological and Immunological Alterations in Egyptian Children with Idiopathic Generalized Seizures
}

\author{
Ola Samir El-Shimi ${ }^{10}$ Amina Ali Farag ${ }^{2}$ Amany Mohammed El-Rebigi ${ }^{3}$ \\ Taghrid Gamaleldin Kharboush ${ }^{4}$ Hanaa El-Sayed Bayomy ${ }^{5}$ Rana Atef Khashaba ${ }^{1}$
}

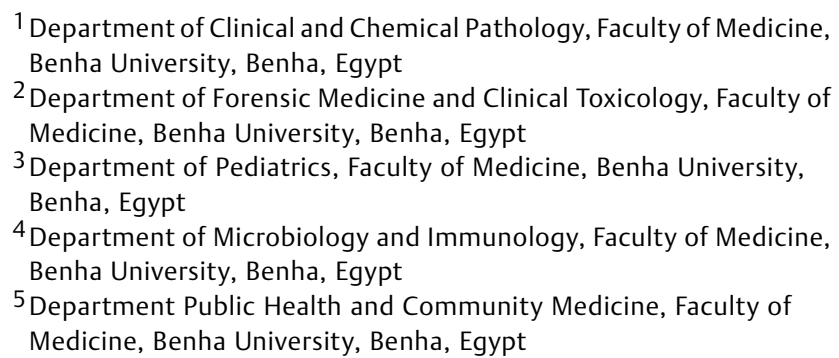

Address for correspondence Ola Samir El-Shimi, MD, Department of Clinical and Chemical Pathology, Faculty of Medicine, Benha University, Benha 13511, Egypt (e-mail: ola.samer@fmed.bu.edu.eg).

J Child Sci 2021;11:e265-e272.

\begin{abstract}
Keywords

- carbamazepine

- immunological effects

- hematological effects

- children

- Egypt

Carbamazepine (CBZ) is one of the oldest antiepileptic drugs (AEDs) that is still used for the treatment of tonic-clonic seizures in children. Long-term use of AEDs induces potential toxic effects that may remain undetermined for a long time. Earlier studies have revealed a wide spectrum of hematological toxicities associated with CBZ. This study was conducted to unveil the toxic effects of carbamazepine as an antiepileptic monotherapy on hematological and immunological parameters in a group of Egyptian pediatric patients using it for different durations. Fifty pediatric epileptics of either sex were enrolled; 38 were taking CBZ as antiepileptic monotherapy for $\geq 6$ months and 12 were newly diagnosed untreated patients. Hematological and immunological parameters studied were compared with their age and sex-matched 15 controls and among groups. CBZ was found more toxic for total leukocyte count, lymphocyte count, serum IgA and IgM levels $(p<0.001,0.001,<0.001,<0.001$, respectively). Hemoglobin level, platelets count, serum $C 4$ level and IgA were negatively correlated with serum CBZ level (Spearman's rho $=-0.62,-0.42,-0.34,-0.13 ; p<0.001,0.008,0.04,0.44$, respectively). CBZ treatment duration associated inversely with platelets, lymphocyte, and eosinophil counts ( $p<0.001,0.03,0.01$, respectively). Epileptic children on CBZ monotherapy had their hematologic and immunologic systems affected, which mandates routine monitoring of these children.
\end{abstract}

\section{Introduction}

Epilepsy is the most common childhood chronic neurologic disorder that affects $0.5 \%$ to $1 \%$ of children. ${ }^{1}$ Long-term use of

received

March 16, 2021

accepted after revision

August 8, 2021
DOI https://doi.org/

$10.1055 / \mathrm{s}-0041-1736156$.

ISSN 2474-5871. antiepileptic drugs (AEDs) is the main treatment to control seizures in approximately $70 \%$ of patients with epilepsy. The failure of seizure control in the remaining $30 \%$ of cases leads
(C) 2021. The Author(s).

This is an open access article published by Thieme under the terms of the Creative Commons Attribution License, permitting unrestricted use, distribution, and reproduction so long as the original work is properly cited. (https://creativecommons.org/licenses/by/4.0/) Georg Thieme Verlag KG, Rüdigerstraße 14, 70469 Stuttgart, Germany 
to what is called drug-resistant epilepsy. ${ }^{2}$ In fact, AEDs are "antiseizure" rather than "antiepileptics," which target symptoms more than the underlying cause of epilepsy. A minimal dose of AED is initially prescribed and regularly titrated according to the half-life and therapeutic and side effects of the drug to adjust the dose to get the optimal therapeutic-seizure control; then, the dose is maintained, and the side effects are monitored. ${ }^{3}$

Carbamazepine (CBZ) is one of the oldest anticonvulsant drugs that are still extensively used in adults and children in developing countries. It is the first-line treatment in focal seizures, effective in generalized tonic-clonic seizures, but it might exacerbate fits in generalized and unclassifiable epilepsies with absences and/or myoclonus. The mechanism of action of CBZ is achieved via action on sodium channels with a dose of 10 to $30 \mathrm{mg} / \mathrm{kg} / \mathrm{day}^{4}$

Both genetic and environmental factors that may affect the pharmacokinetics and pharmacodynamics of CBZ should be considered, especially in children and adolescents. ${ }^{5}$ Furthermore, the effects of age, gender, and race on immune function and response should also be considered. ${ }^{6}$

CBZ has been reported to be associated with several hematological alterations and/or toxicities such as leucopenia, $^{7}$ anemia and agranulocytosis, ${ }^{8}$ and thrombocytopenia. ${ }^{9}$ Also, it has been shown to induce hematological toxicity secondary to bone marrow suppression. ${ }^{10}$

Several studies have been conducted to explore the effect of AEDs on the immune system, but results are usually inconsistent and conflicting. This may be due to various factors such as the interacting effects of drugs and seizures, the genetic background of patients, the pharmacodynamics and pharmacokinetics of AEDs, and the concomitant use of immunosuppressants. Among AEDs; valproate, carbamazepine, phenytoin, vigabatrin, levetiracetam, and diazepam have been found to affect both humoral and cellularmediated immunity. ${ }^{11}$

The data is lacking regarding the hematological and immunological changes in epileptic Egyptian children treated with CBZ. Thus, we conducted the present study to investigate the effect of $\mathrm{CBZ}$ and the duration of its use as a monotherapy in children with idiopathic generalized seizures on both hematological and serum immunological parameters.

\section{Methods}

\section{Study Population}

This case-control study was conducted on 65 children (39 males and 26 females), with a mean age of $8.02 \pm 4.04$ years. The participants were divided into two groups; the patient group included 50 cases ( 30 male and 20 female), with mean age $7.4 \pm 3.97$ years, who were diagnosed with idiopathic generalized tonic-clonic convulsions (GTC), according to the International League Against Epilepsy to exclude other causes of epilepsy than being idiopathic, ${ }^{12}$ and referred to a pediatric neurology outpatient clinic in Benha University Hospitals between March and June 2019. The control group included 15 apparently healthy children selected from general population and were age and sex-matched with the patient group. Cases were prescribed CBZ in a dose of $10 \mathrm{mg} / \mathrm{kg} /$ day. The dose was increased by $5 \mathrm{mg} / \mathrm{kg} /$ day up to $30 \mathrm{mg} / \mathrm{kg} /$ day, whenever indicated. ${ }^{13}$

The patient group was subdivided according to the duration of CBZ treatment into the following: newly diagnosed untreated (12 cases), treated for 6 to 12 months (14 cases), treated for 12 to 24 months (12 cases), and treated for more than 24 months (12 cases).

Exclusionary criteria included any child with idiopathic epilepsy below 2 years of age or above 15 years of age, those treated with AEDs rather than CBZ, diagnosis of any other diseases, or those prescribed any other medications.

\section{Ethical Considerations}

This study was approved by the local ethical committee for research involving human subjects in the Faculty of Medicine, Benha University. Ethical permission and consent were obtained from parents/guardians after being fully informed about the study and its procedures. This study was performed according to the guidelines of the Declaration of Helsinki.

\section{Clinical Assessment}

A full history was taken from all children with special consideration on the developmental status, onset, duration, frequency of seizures, postictal duration, medication including onset and dose of CBZ, and signs of drug hypersensitivity in the form of drug eruption. Assessment of weight, height, and body mass index (BMI) along with thorough neurological examination, an electroencephalogram (EEG) or magnetic resonance imaging (MRI) of the brain was performed on each participant.

\section{Laboratory Investigations}

Peripheral venous blood was aseptically drawn from all enrolled subjects into serum-separating and EDTA tubes, between 8 and 9 AM, after recent viral infections were excluded. Hematological and immunological parameters were assessed in the form of complete blood count (CBC) using Sysmex (XS-500i) and in accordance with age group reference values and serum immunoglobulin ( $\operatorname{IgA}, \operatorname{IgM}, \operatorname{IgG})$ and serum complement $(\mathrm{C} 3, \mathrm{C} 4)$ concentrations with the use of radial immune diffusion (RID) technique and diffusion time of 48 hours (Cat. \#: 4410, 4412, 4411, 4404, 4405 respectively, FAR srl, Verona, Italy). Reference values of the used kits are as follows: IgA 90 to $400 \mathrm{mg} / \mathrm{dl}$, IgM 60 to $280 \mathrm{mg} / \mathrm{dl}$, IgG 800 to $1800 \mathrm{mg} / \mathrm{dl}, \mathrm{C} 3 \mathrm{c} 50$ to $120 \mathrm{mg} / \mathrm{dl}$, and C4 50 to $120 \mathrm{mg} / \mathrm{dl}$.

Therapeutic drug monitoring of CBZ was done in treated cases before the morning dose. The therapeutic reference range was 4 to $12 \mu \mathrm{g} / \mathrm{mL}^{14}$

\section{Statistical Analysis}

Statistical analyses were conducted using STATA/SE version 11.2 for Windows (STATA Corporation, College 
Station, Texas). Data were described as mean \pm standard deviation (SD) for numerical data and number (i.e., percentage) for categorical data. The distribution of numerical data was tested using the Shapiro-Wilk test for normal data. Comparisons between the different study groups were performed using the Fisher exact test (FET) to compare proportions, and the one-way analysis of variance (ANOVA; $F$ ) and the Kruskal-Wallis test were used to compare numerical data as appropriate. A posthoc test using the Bonferroni method was used to detect differences in pairs. The Pearson correlation coefficient $(r)$ and the Spearman correlation coefficient (rho) were used to test for the correlations between serum CBZ levels and studied parameters. Statistical significance was considered at $p<0.05$.

\section{Results}

The study was conducted on 15 healthy children aged between 5.5 and 15 years, 12 newly diagnosed untreated epileptic patients aged between 2 and 14 years, and 38 epileptic patients under CBZ monotherapy aged between 3 and 15 years. All groups were age, sex, and BMI-matched. The patients' body weight and height were significantly lower than healthy children ( $p<0.03$ for each) ( - Table 1 ).

Epileptic patients under treatment were more likely to have less total leukocyte count (TLC) $(p<0.001)$ and lymphocyte count $(p<0.001)$ than untreated children. Serum IgA and IgM levels were significantly lower in epileptic children under treatment compared with newly diagnosed untreated and control children ( $p<0.001$ each) ( -Table 2, - Fig. 1).

Table 1 Demographic characteristics and BMI of studied groups

\begin{tabular}{|l|l|l|l|l|l|}
\hline \multicolumn{2}{|l|}{ Variable } & $\begin{array}{l}\text { Healthy control } \\
(\boldsymbol{n}=\mathbf{1 5})\end{array}$ & $\begin{array}{l}\text { Untreated patients } \\
(\boldsymbol{n}=\mathbf{1 2})\end{array}$ & $\begin{array}{l}\text { Treated patients } \\
(\boldsymbol{n}=\mathbf{3 8})\end{array}$ & $\boldsymbol{p}$-Value \\
\hline \multirow{2}{*}{ Sex } & Female & $6(40.0 \%)$ & $6(50.0 \%)$ & $14(36.84 \%)$ & 0.73 \\
\cline { 2 - 5 } & Male & $9(60.0 \%)$ & $6(50.0 \%)$ & $24(63.16 \%)$ & \\
\hline Age (years) & $9.1 \pm 3.65$ & $6 \pm 4.54$ & $7.84 \pm 3.73$ & 0.12 \\
\hline Weight $(\mathrm{kg})$ & $35.8 \pm 14.26$ & $22.83 \pm 12.39^{\mathrm{a}}$ & $28.47 \pm 15.64$ & $\mathbf{0 . 0 3}$ \\
\hline Height $(\mathrm{cm})$ & $133.2 \pm 15.36$ & $110.33 \pm 30.79^{\mathrm{a}}$ & $120 \pm 20.56$ & $\mathbf{0 . 0 3}$ \\
\hline BMI $\left(\mathrm{kg} / \mathrm{m}^{2}\right)$ & $19.38 \pm 4.1$ & $17.62 \pm 3.55$ & $18.61 \pm 4.54$ & 0.45 \\
\hline
\end{tabular}

Abbreviation: BMI, body mass index; SD, standard deviation.

Note: Data represented as a number (\%) or mean \pm SD. Fisher exact test, one-way analysis of variance (ANOVA), and Kruskal-Wallis test were used as appropriate; ${ }^{\text {a }}$ : significant difference compared with healthy controls.

Table 2 Laboratory findings in studied groups

\begin{tabular}{|c|c|c|c|c|}
\hline Variable & $\begin{array}{l}\text { Healthy control } \\
(n=15)\end{array}$ & $\begin{array}{l}\text { Untreated patients } \\
(n=12)\end{array}$ & $\begin{array}{l}\text { Treated patients } \\
(n=38)\end{array}$ & $p$-Value \\
\hline $\mathrm{Hb}(\mathrm{g} / \mathrm{dl})$ & $11.98 \pm 0.2$ & $11.78 \pm 1.16$ & $12.1 \pm 1.1$ & 1.00 \\
\hline MCV (fl) & $80.32 \pm 1.96$ & $79.95 \pm 4.30$ & $76.26 \pm 7.78$ & 0.07 \\
\hline $\mathrm{MCHC}(\mathrm{pg})$ & $27.24 \pm 0.81$ & $26.17 \pm 2.61$ & $26.32 \pm 2.52$ & 0.44 \\
\hline PLTs $\left(\times 10^{3} / \mu \mathrm{L}\right)$ & $320.4 \pm 7.07$ & $314.33 \pm 175.57$ & $304.31 \pm 84.0$ & 0.07 \\
\hline $\operatorname{TLC}\left(\times 10^{3} / \mu \mathrm{l}\right)$ & $6.16 \pm 1.53$ & ${ }^{\mathrm{a}} 9.74 \pm 2.5$ & ${ }^{\mathrm{b}} 6.2 \pm 1.83$ & $<0.001$ \\
\hline Neutrophils $\left(\times 10^{3} / \mu \mathrm{l}\right)$ & $2.76 \pm 1.45$ & $2.67 \pm 1.2$ & $2.62 \pm 1.13$ & 0.84 \\
\hline Lymphocytes $\left(\times 10^{3} / \mu \mathrm{l}\right)$ & $2.72 \pm 0.3$ & $2.19 \pm 1.39$ & ${ }^{\mathrm{a}} 2.01 \pm 0.76$ & 0.001 \\
\hline Monocytes $\left(\times 10^{3} / \mu \mathrm{l}\right)$ & $0.48 \pm 0.02$ & $0.47 \pm 0.12$ & $0.43 \pm 0.17$ & 0.25 \\
\hline Eosinophils $\left(\times 10^{3} / \mu \mathrm{l}\right)$ & $0.18 \pm 0.04$ & $0.15 \pm 0.16$ & $0.17 \pm 0.12$ & 0.67 \\
\hline Basophils $\left(\times 10^{3} / \mu \mathrm{l}\right)$ & $0.02 \pm 0.004$ & $0.02 \pm 0.02$ & $0.02 \pm 0.007$ & 0.84 \\
\hline $\operatorname{lgA}(\mathrm{mg} / \mathrm{dl})$ & $480.4 \pm 27.89$ & $219 \pm 152.12^{a}$ & $175.91 \pm 103.87^{\mathrm{a}}$ & $<0.001$ \\
\hline $\operatorname{lgM}(\mathrm{mg} / \mathrm{dl})$ & $136.67 \pm 11.04$ & $94.26 \pm 36.22^{a}$ & $72.83 \pm 29.09^{a}$ & $<0.001$ \\
\hline $\operatorname{lgG}(\mathrm{mg} / \mathrm{dl})$ & $841.73 \pm 115.83$ & $1161.75 \pm 895.7$ & $1039.41 \pm 555.05$ & 0.54 \\
\hline $\mathrm{C3c}(\mathrm{mg} / \mathrm{dl})$ & $142.2 \pm 46.37$ & $146.65 \pm 40.23$ & $123.13 \pm 38.06$ & 0.14 \\
\hline $\mathrm{C} 4(\mathrm{mg} / \mathrm{dl})$ & $20.27 \pm 9.59$ & $17 \pm 12.68$ & $21.56 \pm 7.51$ & 0.37 \\
\hline CBZ $(\mu \mathrm{g} / \mathrm{mL})$ & - & - & $7.34 \pm 3.79$ & - \\
\hline
\end{tabular}

Abbreviation: CBZ, carbamazepine; MCHC, mean corpuscular hemoglobin concentration; MCV, mean corpuscular volume; PLT, platelet count; SD, standard deviation; TLC, total leucocyte count.

Note: Data represented as mean \pm SD. one-way analysis of variance (ANOVA) test and Kruskal-Wallis test were used as appropriate, ${ }^{a}$ significant difference compared with controls, bsignificant difference compared with untreated patients. 

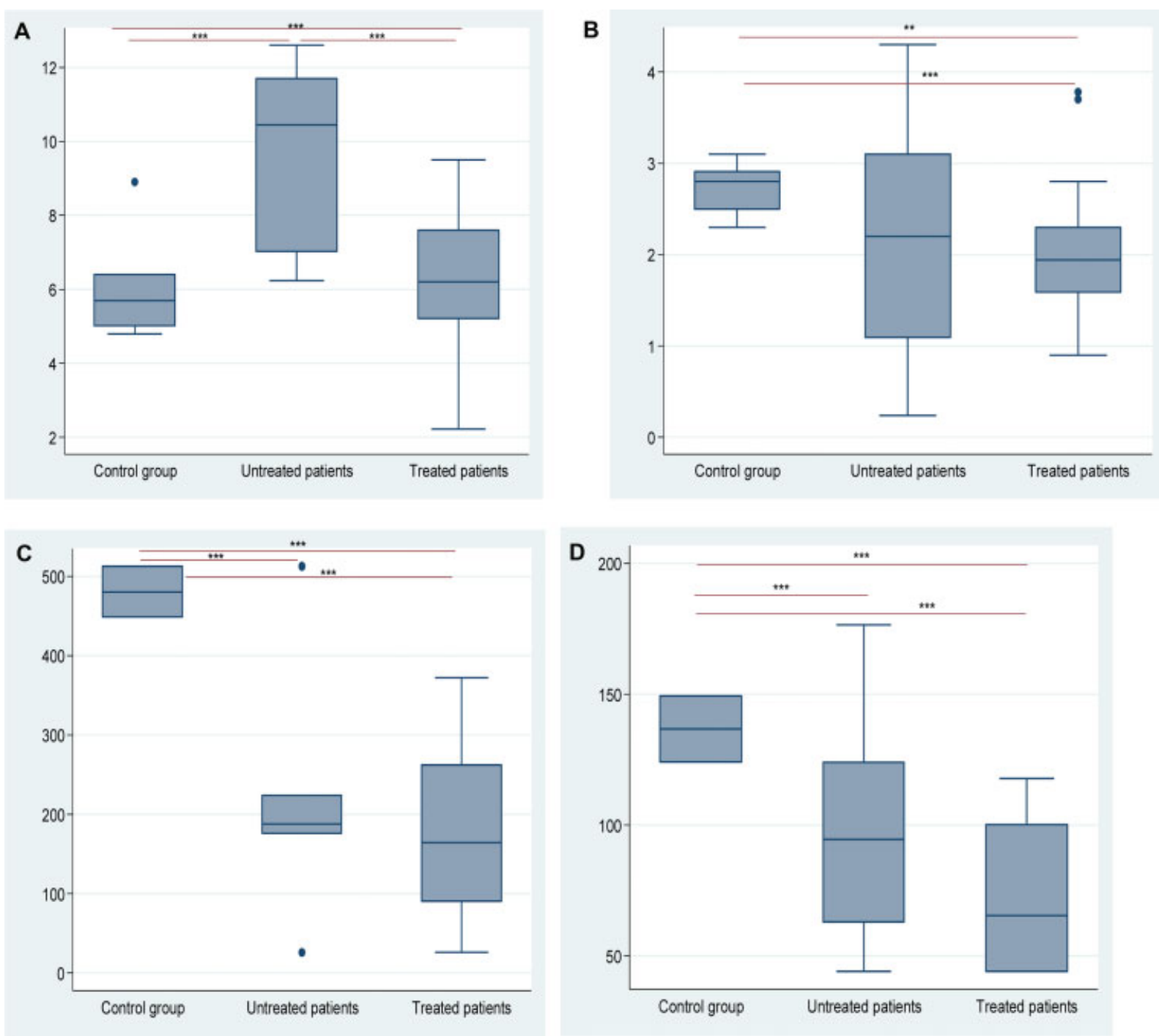

Fig. 1 Differences between the studied groups regarding: (A) total leucocyte count (TLC), (B) lymphocytes, (C) serum IgA, and (D) serum IgM. ${ }^{* *} p<0.001 ;{ }^{* * *} p<0.001$ obtained from the Kruskal-Wallis test and posthoc using the Bonferroni method.

Regarding the correlation between serum CBZ level and different laboratory parameters in epileptic children under treatment, hemoglobin level, platelet count and serum C4 level showed significant negative correlations with serum CBZ level $(r h o=-0.62,-0.42,-0.34 ; p<0.001,0.008,0.04$, respectively). Similarly, there was a negative correlation between the serum levels of CBZ and IgA; however, this was nonsignificant $(r h o=-0.13 ; p=0.44)$ (-Fig. 2).

By studying the effect of CBZ treatment duration on different laboratory parameters; platelets, lymphocyte, and eosinophil counts were significantly decreasing with the increase of treatment duration $(p<0.001,0.03,0.01$, respectively). Meanwhile, monocyte count and serum IgG level in treated patients $>24$ months show significantly lower values more than patients treated for 12 to 24 months $(p<0.001$, 0.01 , respectively) (-Table 3 ).

\section{Discussion}

Epilepsy is the most frequent chronic neurological disease in children. ${ }^{1}$ CBZ is the drug of choice to control GTC seizures. ${ }^{4}$
This case-control study was conducted to investigate the hematological and immunological effects of treatment with CBZ in Egyptian children ( $\leq 15$ years old) with GTC seizures.

In the present study, the untreated patients had significantly lower weight and height compared with healthy children. However, body mass tended to improve with treatment ( - Table 1 ). Many antiepileptic drugs have been linked with weight gain such as valproic acid (VPA), CBZ, gabapentin, pregabalin, and vigabatrin. ${ }^{15,16}$ The higher body weight in epileptic children than healthy matched peers was explained by physical inactivity in epileptic children, lethargy and increased appetite induced by antiepileptic drugs, and potential comorbidities associated with overeating. ${ }^{17}$

In contrast, a retrospective study of 1.1 million adult patients ( $\geq 18$ years old) with epilepsy in Wales reported nonsignificant weight gain in patients, who were treated with CBZ between 12 months before and 12 months after starting treatment. ${ }^{18}$

The results of the current study revealed that epileptic children who were on CBZ treatment had a significant reduction in total leukocytes and lymphocyte counts 

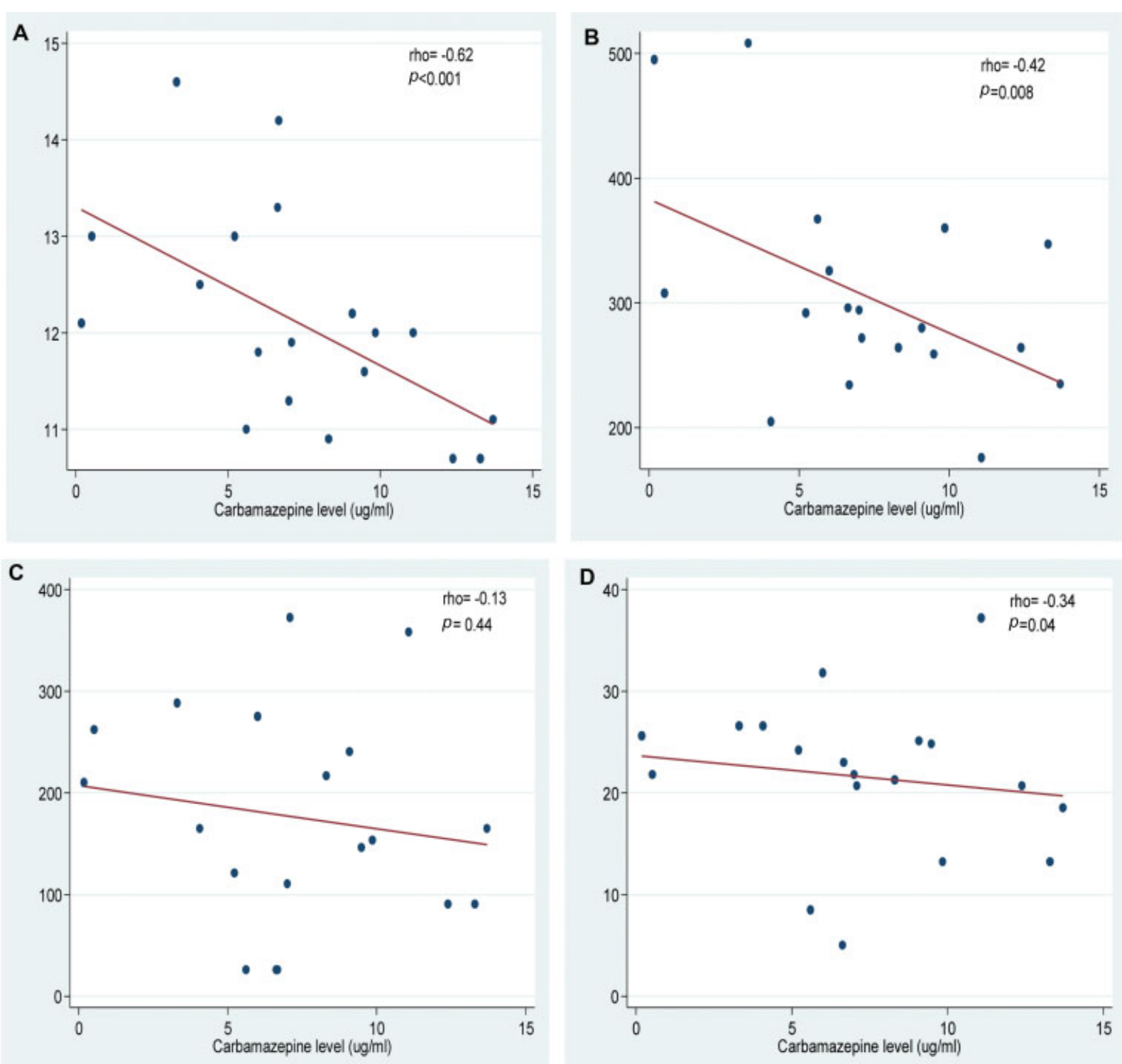

Fig. 2 Correlation study of serum carbamazepine level in treated epileptic patients with: (A) hemoglobin level, (B) platelets count, (C) IgA level, and (D) serum C4 level. rho: Spearman correlation coefficient, $p$ : probability.

compared with the untreated patients (- Table 2). Moreover, platelets, lymphocytes, monocytes, and eosinophils counts were progressively decreased as the duration of CBZ monotherapy increased ( - Table 3 ). In addition, there were significant negative correlation between the serum CBZ level with hemoglobin level ( $r h o=-0.62 ; p<0.001)$ and platelets count (rho $=-0.42 ; p=0.008)$. Correspondingly, the assessment of 137 patients who were on CBZ therapy and 60 patients on oxcarbazepine (OXCBZ) after 3 months of treatment revealed a negative correlation between platelet count and daily doses of both drugs, and five patients (four received CBZ and one received OXCBZ) had a significant reduction in platelets (thrombocytopenia) with increased platelets destruction and reduced platelet survival. ${ }^{19}$

In the current study, CBZ therapy and its duration were associated with reduced white blood cells (WBCs), within the neutral range, in epileptic children. Also, leukopenia was reported in $31.7 \%$ ( 13 out of 41 ) of epileptic Iranian children and adolescents on CBZ therapy after 1 year follow-up, with one patient having to discontinue treatment due to severe leukopenia after 6 months. ${ }^{20} \mathrm{~A}$ follow-up study to investigate leukopenia in 262 adult epileptic patients, half of them were on CBZ therapy and the other half were on other antiepileptic treatments, reported that leukopenia was more likely associated with CBZ than other treatments (21.4\% vs. $13.7 \%)$, and the total leukocytic count was inversely correlated with drug levels. However, leukopenia was not associated with clinical manifestations. ${ }^{21}$ It was suggested that CBZ inhibits colonystimulating factor in bone marrow, which causes the reduction in WBCs, especially in patients with low WBCs counts before the onset of treatment. However, this is commonly reversed even with continuing treatment. ${ }^{22}$

Along with these results, penicillamine, gold, and CBZ were strongly associated with drug-induced agranulocytosis and aplastic anemia in three case-control studies that were conducted in Europe, the United States, and Thailand. ${ }^{23} \mathrm{~A}$ 
Table 3 Variations in laboratory data regarding the duration of CBZ treatment in treated patients

\begin{tabular}{|c|c|c|c|c|}
\hline \multirow[t]{2}{*}{ Variable } & \multicolumn{3}{|c|}{ Treated patients $(n=38)$} & \multirow[t]{2}{*}{$p$-Value } \\
\hline & $\begin{array}{l}6-12 \text { months } \\
(n=14)\end{array}$ & $\begin{array}{l}12-24 \text { months } \\
(n=12)\end{array}$ & $\begin{array}{l}>24 \text { months } \\
(n=12)\end{array}$ & \\
\hline $\mathrm{Hb}(\mathrm{g} / \mathrm{dl})$ & $12.2 \pm 1.12$ & $12 \pm 0.69$ & $12.08 \pm 1.45$ & 0.90 \\
\hline $\mathrm{MCV}(\mathrm{fl})$ & $74.74 \pm 8.08$ & $76.15 \pm 7.61$ & $78.13 \pm 7.86$ & 0.12 \\
\hline MCHC (pg) & $26.13 \pm 2.89$ & $25.25 \pm 2.83$ & $27.62 \pm 0.66$ & 0.11 \\
\hline PLTs $\left(\times 10^{3} / \mu \mathrm{l}\right)$ & $369.43 \pm 96.62$ & $278.17 \pm 54.81$ & $254.5 \pm 29.09^{a}$ & $<0.001$ \\
\hline $\operatorname{TLC}\left(\times 10^{3} / \mu \mathrm{l}\right)$ & $6.36 \pm 2.66$ & $5.54 \pm 1.01$ & $6.68 \pm 1.06$ & 0.15 \\
\hline Neutrophils $\left(\times 10^{3} / \mu \mathrm{l}\right)$ & $2.51 \pm 1.39$ & $2.17 \pm 0.83$ & $3.2 \pm 0.87$ & 0.07 \\
\hline Lymphocytes $\left(\times 10^{3} / \mu \mathrm{l}\right)$ & $2.44 \pm 0.9$ & $1.9 \pm 0.67$ & $1.61 \pm 0.31^{\mathrm{a}}$ & 0.03 \\
\hline Monocytes $\left(\times 10^{3} / \mu \mathrm{l}\right)$ & $0.49 \pm 0.18$ & $0.53 \pm 0.07$ & $0.26 \pm 0.08^{a b}$ & $<0.001$ \\
\hline Eosinophils $\left(\times 10^{3} / \mu \mathrm{l}\right)$ & $0.22 \pm 0.16$ & $0.18 \pm 0.06$ & $0.11 \pm 0.06^{\mathrm{ab}}$ & 0.01 \\
\hline Basophils $\left(\times 10^{3} / \mu \mathrm{l}\right)$ & $0.02 \pm 0.008$ & $0.02 \pm 0.008$ & $0.02 \pm 0.007$ & 0.57 \\
\hline $\lg A(m g / d l)$ & $147.04 \pm 127.15$ & $205.17 \pm 85.67$ & $180.33 \pm 88.48$ & 0.37 \\
\hline $\operatorname{lgM}(\mathrm{mg} / \mathrm{dl})$ & $69.23 \pm 44.56$ & $84.22 \pm 25.9$ & $63.85 \pm 33.94$ & 0.21 \\
\hline $\operatorname{lgG}(\mathrm{mg} / \mathrm{dl})$ & $1154.93 \pm 809.33$ & $1164.83 \pm 339.6$ & $779.22 \pm 197.05^{b}$ & 0.01 \\
\hline C3c (mg/dl) & $127.5 \pm 54.14$ & $136.48 \pm 20.59$ & $104.68 \pm 19.89$ & 0.10 \\
\hline $\mathrm{C} 4(\mathrm{mg} / \mathrm{dl})$ & $19.6 \pm 11.43$ & $23.87 \pm 2.26$ & $21.53 \pm 4.44$ & 0.31 \\
\hline
\end{tabular}

Abbreviations: CBZ, carbamazepine; MCHC, mean corpuscular hemoglobin concentration; MCV, mean corpuscular volume; PLT, platelet count; SD, standard deviation; TLC, total leucocyte count.

Note: Data represented as mean \pm SD. one-way analysis of variance (ANOVA) test and Kruskal-Wallis test were used as appropriate, ${ }^{a}$ significant difference compared with patients with 6-12 months duration of treatment, ${ }^{\mathrm{b}}$ significant difference compared with patients with $12-24$ months duration of treatment.

controlled trial was performed to investigate hematological changes after 1 year of antiepileptic therapy showed that antiepileptic drugs were associated with a significant reduction in the total and differential leucocytes, red blood cell (RBC) count, mean corpuscular volume (MCV), and mean corpuscular hemoglobin concentration (MCHC) ${ }^{24}$ Nonetheless, the exact mechanism underlying the hematological effects of antiepileptic drugs remains unclear and needs further investigations.

Thus, hematological monitoring is required for patients on antiepileptic therapy, particularly CBZ. CBZ should be discontinued if there is severe blood dyscrasias or severe symptoms such as sore throat, fever, and rash. ${ }^{25}$ It was suggested to withdraw CBZ if total leucocyte count (TLC) $<1500 / \mathrm{mm}^{3}$, neutrophils $<1500 / \mathrm{mm}^{3}$, or platelets $<100,000 / \mathrm{mm}^{3} .{ }^{26}$ In children, the therapeutic dose of CBZ, enough to control seizure with no or minimal side effects, should be determined according to the age, weight and other comedications of individual patients and given as multiple doses per day. This is due to the fact that immature physiological systems in children can affect drug pharmacokinetics and elimination. ${ }^{5}$

In contrast, hematological changes in 50 epileptic patients who were on CBZ therapy for at least 1 month and aged 15 to 70 years old and 50 controls in Khartoum, Sudan, found no significant differences in $\mathrm{Hb} \%$, Hct, RBC, TLC, neutrophils, lymphocytes, and platelets between patients and controls, and between patients with different disease severity, treatment duration and dose of CBZ. ${ }^{27}$ In addition, an experimental trial was conducted on Wistar rats to compare hematological changes after administration of CBZ, phenytoin (PHT) and $\mathrm{CBZ}+$ PHT with the control group that was given distilled water. The trial found no significant difference in packed cell volume, $\mathrm{Hb} \%$ and platelets, significant reduction in RBCs, and significant increased lymphocytes and neutrophils following the administration of CBZ. There were nonsignificant changes with the other treatment lines. ${ }^{28}$

Concerns have emerged toward the immunosuppressive effects of AEDs, particularly CBZ. However, whether immunosuppression is due to AEDs or epilepsy is a controversy. Our results showed a significant reduction in serum levels of IgA and IgM in epileptic children on CBZ therapy compared with untreated patients and healthy controls. There were inverse relationships between IgG and the duration of treatment and between IgA and C4 and serum levels of CBZ.

Correspondingly, a follow-up study of 71 epileptic children above 2 years old from Iran investigated the effects of AEDs, namely, CBZ that was given to 33 patients, phenobarbital (PB) was given to 16 patients, and VPA was given to 22 patients based on their immunoglobulin's levels. After 6 months, 11 children had a reduction in at least one immunoglobulin. Of these, eight patients were treated with CBZ. IgA was reduced in three patients and IgG was reduced in five patients. However, the reduction in immunoglobulin was not associated with recurrent infections. ${ }^{29}$ Similarly, the Dutch study of epilepsy in childhood found that after 9 to 18 months of CBZ monotherapy in 34 children, there were a significant decrease in IgA and IgG4 levels 
$(p<0.01)$, but there was no significant change in IgM levels. ${ }^{30}$ Along with our findings, a prospective study of 61 epileptic children above 2 years age from Iran who had their IgG subclasses estimated before and after 6 months of antiepileptic monotherapy with CBZ, VPA, or PB, revealed a reduction in at least one IgG subclass in 6 patients with five of them being treated with $\mathrm{CBZ} .^{29}$

Case studies of epileptic patients of different ages reported a reduction in immunoglobulin levels following CBZ therapy. Reduction in IgG and IgM that was improved with the elimination of clinical manifestations after discontinuation of CBZ intake was reported by Ozaras et al, ${ }^{31}$ IgA and IgG levels drop was reported by Castro et al, ${ }^{32}$ and dropin $\operatorname{IgG}$, IgA, and IgM was reported by Hayman $\&$ Bansal $^{33}$ and Go. ${ }^{34}$

In contrast, there were no significant differences in IgG and IgA between epileptic children and controls and between untreated and treated children (using CBZ or VPA monotherapy). ${ }^{35}$

The mechanism of the immunosuppressive effects observed in epileptic patients on AEDs, including CBZ, remains unclear. It was suggested that immunosuppression can be due to suppression of B-lymphocytes induced by the drugs. ${ }^{32}$ An interaction between the central nervous system (CNS) and immune system was proposed. ${ }^{36}$ The genetic role was also involved, and reduction in immunoglobulin levels due to CBZ was linked to HLA-A2. ${ }^{37,38}$ However, the role of the base disease was incriminated. Further studies are required to investigate the role of $\mathrm{CBZ}$ and predisposing factors implicated in this immunosuppression.

CBZ therapy was showed to be associated with a reduction in humoral immunity, which might be evidenced clinically by recurrent episodes of infections. Thus, routine assessment of immunoglobulin levels before and during therapy should be considered.

This study showed a negative correlation between serum CBZ levels and C4 levels. Complement dysregulation was linked to a poor prognosis of epilepsy. A significant increase in plasma levels of $\mathrm{C} 4$ and $\mathrm{C} 1 \mathrm{q}$ was detected in patients with uncontrolled seizures compared with those with controlled seizures. However, there were no significant changes in the plasma levels of complements in epileptic patients treated with CBZ. The lack of significant findings could be due to few patients treated with CBZ $(n=18) .{ }^{39}$ In addition, a casecontrol study was performed to investigate the immunologic effects of AEDs, which revealed no significant differences in C4 between epileptic patients treated with phenytoin $(n=30)$, CBZ $(n=22)$, untreated patients $(n=38)$, and healthy controls $(n=40)$. Meanwhile, C3 was significantly higher in untreated patients and CBZ-treated patients compared with controls. ${ }^{40}$ In our study, C3 was higher in untreated patients $(146.65 \pm 40.23 \mathrm{mg} / \mathrm{dl})$ than in controls $(142.2 \pm 46.37 \mathrm{mg} / \mathrm{dl})$ and treated patients $(123.13 \pm 38.06$ $\mathrm{mg} / \mathrm{dl}$ ), but these differences were statistically nonsignificant. The reduction in C3 and C4 in treated patients can be due to that most of them were controlled, since only four children (10.53\%) had seizures during the month preceding the study (data is not shown).
The main limitation of this study was the relatively small number of cases that regularly took CBZ in the prescribed doses to study the exact effect of the drug.

Overall, this study provides evidence of the hematologic and immunologic effects of CBZ monotherapy in epileptic children. However, the exact mechanisms underlying these effects remain unclear and need further investigation in the form of lymphocyte subsets count, activity, and effector function.

Conflict of Interest

None declared.

\section{References}

1 Aaberg KM, Gunnes N, Bakken IJ, et al. Incidence and prevalence of childhood epilepsy: a nationwide cohort study. Pediatrics 2017; 139(05):e20163908

2 Pulido F L, Pulido F M, Quesada J P, Muruzabal P J, Mendioroz I M. Comparative case-control study of homocysteine, vitamin B 12, and folic acid levels in patients with epilepsy. Neurol 2017;32 (07):440-445

3 Chong DJ, Lerman AM. Practice update: review of anticonvulsant therapy. Curr Neurol Neurosci Rep 2016;16(04):39

4 Rosati A, De Masi S, Guerrini R. Antiepileptic drug treatment in children with epilepsy. CNS Drugs 2015;29(10):847-863

5 Djordjevic N, Jankovic SM, Milovanovic JR. Pharmacokinetics and pharmacogenetics of carbamazepine in children. Eur J Drug Metab Pharmacokinet 2017;42(05):729-744

6 Thomas C, Moridani M. Interindividual variations in the efficacy and toxicity of vaccines. Toxicology 2010;278(02):204-210

7 Porter RJ. How to initiate and maintain carbamazepine therapy in children and adults. Epilepsia 1987;28(Suppl 3):S59-S63

8 Hart RG, Easton JD. Carbamazepine and hematological monitoring. Ann Neurol 1982;11(03):309-312

9 Schweiger FJ, Kelton JG, Messner H, et al. Anticonvulsant-induced marrow suppression and immune thrombocytopenia. Acta Haematol 1988;80(01):54-58

10 Perucca E, Beghi E, Dulac O, Shorvon S, Tomson T. Assessing risk to benefit ratio in antiepileptic drug therapy. Epilepsy Res 2000;41 (02):107-139

11 Beghi E, Shorvon S. Antiepileptic drugs and the immune system. Epilepsia 2011;52(Suppl 3):40-44

12 Fisher RS, Cross JH, French JA, et al. Operational classification of seizure types by the International League Against Epilepsy: Position Paper of the ILAE Commission for Classification and Terminology. Epilepsia 2017;58(04):522-530

13 Johannessen SI, Landmark CJ. Antiepileptic drug interactions principles and clinical implications. Curr Neuropharmacol 2010;8 (03):254-267

14 Patsalos PN, Berry DJ, Bourgeois BFD, et al. Antiepileptic drugsbest practice guidelines for therapeutic drug monitoring: a position paper by the subcommission on therapeutic drug monitoring, ILAE Commission on Therapeutic Strategies. Epilepsia 2008;49(07):1239-127

15 Ben-Menachem E. Weight issues for people with epilepsy-a review. Epilepsia 2007;48(Suppl 9):42-45

16 Verhaegen AA, Van Gaal LF. Drug-induced obesity and its metabolic consequences: a review with a focus on mechanisms and possible therapeutic options. J Endocrinol Invest 2017;40(11): 1165-1174

17 Ladino LD, Téllez-Zenteno JF. Epilepsy and obesity: a complex interaction. In: Mula M, ed. The Comorbidities of Epilepsy. Academic Press; Massachusetts, United States; 2019

18 Pickrell WO, Lacey AS, Thomas RH, Smith PEM, Rees MI. Weight change associated with antiepileptic drugs. J Neurol Neurosurg Psychiatry 2013;84(07):796-799 
19 Tutor-Crespo MJ, Hermida J, Tutor JC. Relation of blood platelet count during carbamazepine and oxcarbazepine treatment with daily dose, and serum concentrations of carbamazepine, carbamazepine-10, 11-epoxide, and 10-hydroxycarbazepine. Biomed Pap Med Fac Univ Palacky Olomouc Czech Repub 2007;151(01):91-94

20 Asadi-Pooya AA. Risk factors for carbamazepine-induced leukopenia in children and adolescents. J Pediatr Neurol 2005;03(04): 233-235

21 Hughes JR, DeTolve-Donoghue M. Chronic leukopenia associated with carbamazepine and other antiepileptic drugs. J Epilepsy 1995;8(04):282-IN10

22 Daughton JM, Padala PR, Gabel TL. Careful monitoring for agranulocytosis during carbamazepine treatment. Prim Care Companion J Clin Psychiatry 2006;8(05):310-311

23 Kaufman DW, Kelly JP, Jurgelon JM, et al. Drugs in the aetiology of agranulocytosis and aplastic anaemia. Eur J Haematol Suppl 1996; 60:23-30

24 Jawad S, Mercer A, Jamil N, Richens A. Haematological values of epileptic patients entering drug trials. Int J Clin Pharmacol Res 1988;8(05):363-366

25 Kumar S. Anticonvulsant-hypersensitivity syndrome in a child. Neurol India 2003;51(03):427

26 Albers LJ, Hahn RK, Reist C. Handbook of Psychiatric Drugs. Current Clinical Strategies Publishing California, United States; 2005

27 Ali NH, Humeida AAK. Assessment of haematological parameters in patients under carbamazepine antiepileptic drug treatment. Afr J Haematol Oncol 2017;6:15-19

28 Aliyu $\mathrm{H}$. Effects of administration of carbamazepine and/or phenytoin on haematological parameters in wistar rats. Afr J Pharm Pharmacol 2013;7(23):1585-1591

29 Ashrafi M, Hosseini SA, Abolmaali S, et al. Effect of anti-epileptic drugs on serum immunoglobulin levels in children. Acta Neurol Belg 2010;110(01):65-70

30 Callenbach PMC, Jol-Van Der Zijde CM, Geerts AT, et al; Dutch Study of Epilepsy in Childhood. Immunoglobulins in children with epilepsy: the Dutch Study of Epilepsy in Childhood. Clin Exp Immunol 2003;132(01):144-151

31 Ozaras N, Goksugur N, Eroglu S, Tabak O, Canbakan B, Ozaras R. Carbamazepine-induced hypogammaglobulinemia. Seizure 2012;21(03):229-231

32 Castro AP, Redmershi MG, Pastorino AC, de Paz JA, Fomin AB, Jacob $\mathrm{CM}$. Secondary hypogammaglobilinemia after use of carbamazepine: case report and review. Rev Hosp Clin Fac Med Sao Paulo 2001;56(06):189-192

33 Hayman G, Bansal A. Antibody deficiency associated with carbamazepine. BMJ 2002;325(7374):1213

34 Go T. Carbamazepine-induced IgG1 and IgG2 deficiency associated with B cell maturation defect. Seizure 2004;13(03): 187-190

35 Lenti C, Masserini C, Peruzzi C, Guareschi Cazzullo A. Effects of carbamazepine and valproate on immunological assessment in young epileptic patients. Ital J Neurol Sci 1991;12 (01):87-91

36 Spickett GP, Gompels MM, Saunders PW. Hypogammaglobulinaemia with absent B lymphocytes and agranulocytosis after carbamazepine treatment. J Neurol Neurosurg Psychiatry 1996;60(04): 459

37 Shakir RA, Behan PO, Dick H, Lambie DG. Metabolism of immunoglobulin A, lymphocyte function, and histocompatibility antigens in patients on anticonvulsants. J Neurol Neurosurg Psychiatry 1978;41(04):307-311

38 Gilhus NE, Aarli JA, Thorsby E. HLA antigens in epileptic patients with drug-induced immunodeficiency. Int J Immunopharmacol 1982;4(06):517-520

39 Kopczynska M, Zelek WM, Vespa S, et al. Complement system biomarkers in epilepsy. Seizure 2018;60:1-7

40 Başaran N, Hincal F, Kansu E, Ciğer A. Humoral and cellular immune parameters in untreated and phenytoin-or carbamazepine-treated epileptic patients. Int J Immunopharmacol 1994;16 (12):1071-1077 